\title{
Umbilical metastasis: a report case and review of the literature
}

\author{
Karima Idrissi Serhrouchni*, Hinde El Fatemi, Laila Chbani, Taoufik Harmouch and Afaf Amarti \\ *Correspondence: idrissisehrouchni@yahoo.fr \\ Department of Pathology, Hassan II University Hospital, Fez, Morocco.
}

\begin{abstract}
Sister Mary Joseph's nodule is a metastatic umbilical lesion secondary to a primary malignancy of any viscera. It can be a presenting symptom (a sign of undiagnosed malignancy) or a sign of progression or recurrence in a known case and is usually associated with a poor prognosis. Its incidence is $1 \%-3 \%$ of all intra-abdominal or pelvic malignancies. We report an umbilical metastasis in a case of rectal carcinoma. The clinicopathologic features are discussed, and the related literature is briefly reviewed.

Keywords: Sister marie joseph's nodule, umbilical metastasis, rectal cancer, primary malignancy, pelvic malignancies
\end{abstract}

\section{Background}

Cutaneous metastases localised to the umbilicus are named "Sister Mary Joseph's nodules". In 1949 Sir Hamilton Bailey initially used this eponym in his book"Physical Signs in Clinical Surgery" to describe umbilical metastases, in honour of Sister Mary Joseph, who was the first to note the link between umbilical nodules and intra abdominal malignancy $[1,2]$.

It is aninconspicuous and uncommon clinical sign, which not only shows the presence of visceral malignancy but also reveals the poor prognosis of these malignancies $[3,4]$. Stomach and colon being most common in men, and ovary, in women. Cases of metastasis from organs such as the cecum, endometrium, pancreas, gallbladder, prostate, and lung, and from unknown primaries have also been reported. The lesion is seen more often in women $[\mathbf{5 , 6 ]}$.

\section{Case report}

A 28-year-old man without any history of colon cancer or any other predisposing factors, had consulted for a bourgeoning lesion of the umbilic, rectal bleeding and weight loss for 2 months duration. Rectal exam did not reveal any palpable masses or firmness. Physical examination revealed an erythematous, painful and firm subcutaneous umbilical nodule, that measures $2 \mathrm{~cm}$ in diameter.The rest of the physical examination was unremarkable, including freedom of peripheral lymph nodes. Colonoscopy showed an ulcerobourgeoning process localized to the medium portion of the rectum. Abdominal CT demonstrated an irregular rectal thickening with a subcutaneous umbilical nodule without lymphadenopathy, peritoneal implant or liver metastasis. Upper fibroscopywas normal. Routine blood chemistry investigations and chest radiography were normal.

Rectal biopsy confirmed the diagnosis of well differentiated rectal adenocarcinoma. The histological study of nodule's biopsy showed, in the dermis, a carcinomatous proliferation of glandular architecture (Figure 1). The tubes were of variable size, lined by cubical and basophilic epithelium, demonstrating moderate nuclear atypia and rare mitoses (Figure 2). Based on these data, the diagnosis of Sister Mary Joseph's nodule was confirmed.

Considering the advanced stage of the disease, patient was referred to the department of oncology for palliative chemotherapy. The patient is currently receiving treatment.

\section{Discussion}

The occurrence of cutaneous metastases from malignant neoplasms ranges in from $1 \%$ to up to $9 \%$ of individuals, as determined at autopsy. Those metastases to the umbilicus are uncommon and represent only $10 \%$ of all secondary tumors which have spread to the skin [1]. Epidemiological studies showed that this condition predominates in females [7].

In the majority ofcases, the finding of an umbilical nodule represents recurrence or dissemination of known malignancies. Occasionally, however, this may be the initial presentation of the primary disease in up to $30 \%$ of the cases $[1,8,9]$.

Most often, the umbilical metastasis is an adenocarcinoma, rarely a squamous carcinoma, melanoma or sarcoma $[4,10,11]$. If these nodules are secondary tumors deposits then the source of the primary tumors may be from the gastrointestinal (35-65\%) and genitourinary (12-35\%) tract. In addition, in 3-6\% of cases it originates from haematological malignancies, or lung and breast cancers. In $15 \%$ to $30 \%$ of patients the source of the primary site of the tumors remains unknown $[1,9,10,11]$.

A full understanding of the mechanism where by the tumor spread to the umbilicus remains unclear. However, several anatomical criteria and several hypothesis have been proposed, including direct invasion, through continuous extension, of the anterior peritoneum, which is the most common; lymphatic spread via the axilliary, inguinal, para-aortic, internal mammary and external iliac lymph nodes; hematogenous spread through arterial and venous seeding; and finally direct extension along the embryonic ligaments $[\mathbf{1 , 4 , 8 ]}$.

Clinically, Sister Mary Joseph's nodules usually present as a

(C) 2013 Serhrouchni et al; licensee Herbert Publications Ltd. This is an Open Access article distributed under the terms of Creative Commons Attribution License (http://creativecommons.org/licenses/by/3.0). This permits unrestricted use, distribution, and reproduction in any medium, provided the original work is properly cited. 

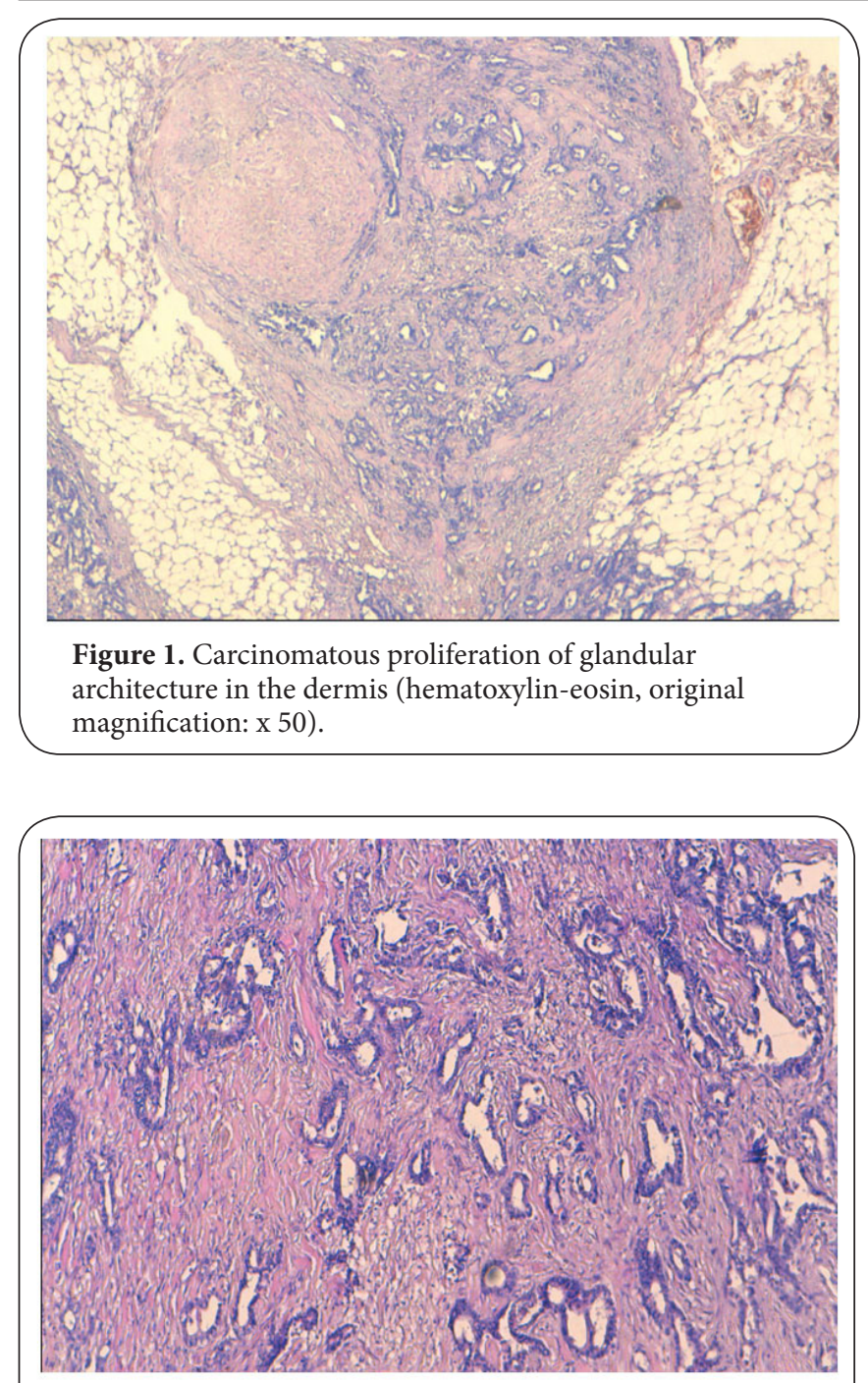

Figure 2. The tubes were of variable size, lined by cubical and basophilic epithelium, containing moderate nuclear atypia and rare mitoses (hematoxylin-eosin, original magnification: $\mathrm{x} 100)$.

painful lump on the anterior abdominal wall. It has irregular margins and a hard fibrous consistency. The surface may be ulcerated and necrotic, with either blood, serous, purulent, or mucous discharge from it. The size of the nodule usually ranges from 0.5 to $2 \mathrm{~cm}$, although some nodules may reach up to $10 \mathrm{~cm}$ in size. High-resolution ultrasound (US) helps to clarify the clinical findings by detecting solid umbilical nodules, even if the diagnosis is difficult to make clinically. Moreover, careful examination and imaging of the abdominal contents may also point to the diagnosis $[1,4,10,12]$.

Its unspectacular appearence can lead to many misdiagnosis, and this lesion can discuss the differencial diagnosis with umbilical hernia, hypertrophic scar, umbilical endometriosis, pilonidal sinus, pyogenic granuloma, lymphangioma, and primary carcinoma $[3,4,5]$. Histopathology including immunohistochemistry plays a vital role in confirming or suggesting possible sites of primary tumors.

Usually, the presence of an umbilical metastasis indicates a poor prognosis, is the sign of advanced neoplastic disease. The survival of these patients without treatment has been reported to range from 2 to 11 months from the time of initial diagnosis $[1,3,4]$.

However, some factors seem to influence the prognosis of such patients, so direct invasion by the peritoneum is associated with a worseprognosis, the nature of the primary tumor, the time of onset of umbilical metastasis, the prognosis seem more favorable when the metastasis is discovered before the primary tumor only when it is discovered after treatment. Finally, the type of treatment, despite some authors proposing only palliative treatment, recent studies have demonstrated thatthere is a better survival ( 21 months) for patients if theyare treated with a combination of surgery and adjuvant therapy instead of surgery alone (7.4 months) or chemotherapy alone (10.3 months) $[1,6]$.

\section{Conclusion}

A careful examination of all umbilical lesions is recommended, especially in those patients with gastrointestinal and genitourinary tract malignancies. All umbilical mass lesions should be biopsied to determinate the pathological nature of the lesion and to offer the patient the best survival probability with a combination of surgery and adjuvant therapy.

\section{Competing interests}

The authors declare that they have no competing interests.

\section{Authors' contributions}

All authors read and approved the final manuscript.

\section{Acknowledgement}

We thank the editor and the anonymous

reviewers for their constructive comments, which helped us to improve the manuscript.

\section{Publication history}

Editor: Han-Seung yoon, lida Municipal Hospital, Japan.

EIC: Markus H. Frank, Harvard Medical School, USA.

Received: 13-May-2013 Revised: 07-Jun-2013

Accepted: 25-Jul-2013 Published: 03-Aug-2013

\section{References}

1. Gabriele R, Conte M, Egidi F and Borghese M. Umbilical metastases: current viewpoint. World J Surg Oncol. 2005; 3:13. | Article | PubMed Abstract | PubMed Full Text

2. Trebing $D$ and Goring HD. [The umbilical metastasis. Sister Mary Joseph and her time]. Hautarzt. 2004; 55:186-9. | Article | PubMed

3. A. Malani, C. Gupta, L. Kapadia: Unusual Presentation Of A Rare Tumor: Umbilical Metastasis (Sister Mary Joseph's Nodule) Of Malignant Peritoneal Mesothelioma. The Internet Journal of Family Practice. 2005; Volume 4 Number 1.

4. Ioannidis O, Cheva A, Stavrakis T, Paraskevas G, Papadimitriou N, Kakoutis E and Makrantonakis A. Sister Mary Joseph's nodule as the sole presenting sign of gastric signet ring cell adenocarcinoma. Gastroenterol 
Serhrouchni et al. Pathology Discovery 2013,

http://www.hoajonline.com/journals/pdf/2052-7896-1-3.pdf

Clin Biol. 2010; 34:565-8. | Article | PubMed

5. Deb P, Rai RS, Rai R, Gupta E and Chander Y. Sister Mary Joseph nodule as the presenting sign of disseminated prostate carcinoma. $J$ Cancer Res Ther. 2009; 5:127-9. | Article | PubMed

6. Palaniappan M, Jose WM, Mehta A, Kumar K and Pavithran K. Umbilical metastasis: a case series of four Sister Joseph nodules from four different visceral malignancies. Curr Oncol. 2010; 17:78-81. | Article | PubMed Abstract | PubMed Full Text

7. Touraud JP, Lentz N, Dutronc $Y$, Mercier E, Sagot $P$ and Lambert D. [Umbilical cutaneous metastasis (or Sister Mary Joseph's nodule) disclosing an ovarian adenocarcinoma]. Gynecol Obstet Fertil. 2000; 28:719-21. | Article | PubMed

8. Tsai HW, Yuan CC and Wang PH. Umbilicus as the only site of metastasis in recurrent ovarian cancer. J Chin Med Assoc. 2006; 69:233-5. | Article I PubMed

9. Colla TG, Lovatto L and Duquia RP. Case for diagnosis: umbilical metastasis of pancreatic carcinoma (Sister Mary Joseph's Nodule). An Bras Dermatol. 2009; 84:297-8. | Article | PubMed

10. Zadeh VB, Kadyan R, Al-Abdulrazzaq A, Al-Otaibi S, Sarhan A and Najem N. Sister Mary Joseph's nodule: a case of umbilical cutaneous metastasis with signet ring cell histology. Indian J Dermatol Venereol Leprol. 2009; 75:503-5. | Article | PubMed

11. Papalas JA and Selim MA. Metastatic vs primary malignant neoplasms affecting the umbilicus: clinicopathologic features of $\mathbf{7 7}$ tumors. Ann Diagn Pathol. 2011; 15:237-42. | Article | PubMed

12. Ching AS and Lai CW. Sonography of umbilical metastasis (Sister Mary Joseph's nodule): from embryology to imaging. Abdom Imaging. 2002; 27:746-9. | Article | PubMed

\section{Citation:}

Idrissi Serhrouchni K, El Fatemi H, Chbani L, Harmouch T and Amarti A. Umbilical metastasis: a report case and review of the literature. Pathol Discov. 2013; 1:3.

http://dx.doi.org/10.7243/2052-7896-1-3 